\title{
GEOMORFOLOGIA DA PLATAFORMA CONTINENTAL DO ESTADO DE SÃO PAULO
}

\section{LUIS AMÉRICO CONTI ${ }^{1} \&$ VALDENIR VERONESE FURTADO ${ }^{1}$}

\begin{abstract}
Resumo Esta pesquisa teve como objetivo a análise geomorfológica da região de Plataforma Continental do Estado de São Paulo, mais especificamente a área que compreende a porção centro-norte do Embaimento de Santos (de Cananéia a Ilha Grande). Foram elaborados modelos digitais de terreno (MDTs) da plataforma continental a partir da digitalização de 65260 pontos cotados obtidos através de folhas de bordo da Diretoria de Hidrografia e Navegação (DHN) a partir dos quais foi elaborado uma grade batimétrica com precisão de 200 metros. O Modelo Digital de Terreno foi, então, submetido a uma série de modelagens objetivando a identificação e caracterização de feições morfo-sedimentares associadas ao regime de variação do nível do mar e processos atuais, como análises de superfície de tendência, declividades e orientação do relevo e extração de paleo-drenagens. Foram realizadas, também, correlações, em ambientes de Sistema de Informações Geográficas (SIGs), das informações morfológicas com a distribuição de sedimentos superficiais. Foi possível identificar e analisar uma série de feições morfo-sedimentares como faixas de declives associadas a antigos níveis de estabilização do nível do mar, sistemas de paleo-vales bem conectados com desembocaduras atuais dos principais rios da costa do estado de São Paulo, zonas de anomalias sedimentares e topográficas associadas a áreas de maior erosão ou deposição e zonas de altos teores de carbonatos, que associadas a mudanças na rede de paleo-vales, indicam o posicionamento da faixa do Último Máximo Regressivo (UMR) assim como sua posterior evolução.
\end{abstract}

Palavras chave: Plataforma continental, sedimentação quaternária, modelos digitais de terreno, SIG.

\begin{abstract}
GEOMORPHOLOGY OF SÃO PAULO STATE CONTINENTAL SHELF, BRAZIL. The objective of this paper is the geomorphological analysis of the of the São Paulo State continental shelf, specifically, the central portion of São Paulo Bight, using techniques based on digital data treatment and computer modeling. A Digital Terrain Model was elaborated using bathymetric data acquired by Brazilian Navy. 65,260 points were digitalized in order to obtain a regular grid with 3,692 lines and 2,325 rows, with cell's dimension of 200 meters. The bathymetric DTM was submitted to different kinds of mathematical treatments in order to identify features associated with sea-level still stands and paleo-geographical processes. The DTM analysis resulted on several products such as trend surface analysis, paleo valleys networks, aspect and slope distribution. It were also obtained, with geographic information systems techniques, spatial correlation between bathymetric data and sedimentological parameters. The analysis of terrain anomalies (trend surface) and relief slope and aspect distribution show a series of features which are probably related to sea-level stillstands. The paleo valley network indicated a good correlation with positions of modern coastal rivers systems. The set of all information allowed identification of the sea-level during Last Glacial Maximum (LGM) and its evolution.
\end{abstract}

Keywords: Continental shelf, Quaternary Sedimentation, Digital Terrain Model, GIS.

INTRODUÇÃO Os estudos sistemáticos envolvendo ambientes de sedimentação em margem continentais são relativamente recentes. Enquanto a zona costeira tem sido estudada detalhadamente desde o Séc.XVIII, as regiões mais profundas da plataforma continental e talude, apenas foram alvos de investigações geológica/geomorfológicas a partir da metade do século XX, sendo os trabalhos mais detalhados, e com suporte mais preciso de dados, realizados nos últimos 30 anos. Mesmo com tais esforços nas ultimas décadas, muitos aspectos das margens continentais permanecem ainda desconhecidos ou controversos, devido às dificuldades inerentes aos estudos destes ambientes, que apresentam uma grande variação de processos físicos e geológicos atuantes (Drake \& Burk, 1974).

As análises geomorfológicas em plataforma continentais são, na maioria dos casos, adaptações e generalizações de técnicas originalmente desenvolvidas para regiões emersas, onde as principais feições identificadas e analisadas são funções de processos sub-aéreos regressivos. As principais aplicações destas metodologias referem-se a estudos morfométricos, ligados à evolução das feições submersas, associadas, na maior parte, a registros de redes de paleo-drenagens. Há, na literatura uma série de trabalhos envolvendo a relação entre feições submersas e processos sub-aéreos, sendo que a maioria deles estabelece meios qualitativos baseados principalmente na análise de dados primários de batimetria a partir de cartas ou registros de sonar de varredura lateral como em Swift et al., 1984; Wagle \& Veerayya, 1996; Goff et al., 1999 e Orange, 1999, entre outros. Por outro lado, métodos de cunho quantitativo, foram desenvolvidos visando o estabelecimento de valores e dimensões para as feições batimétricas associadas a processos de variação do nível do mar.

Os primeiros trabalhos realizados nessa linha foram elaborados pela escola francesa, principalmente por Proud'Homme, 1970 e 1972; Naudin, 1971, Griboulard, 1980 e Griboulard \& Proud'Homme, 1985. A elaboração destes produtos, relativos a morfologia do relevo, apresentam ligações diretas com descontinuidades relacionadas à heterogeneidade do substrato, quer seja na forma de anisotropias sedimentares como planos de descontinuidade, variações litológicas e faciológicas, ou na forma de anisotropias estruturais ou tectônicas como falhas ou dobras que caracterizam eventos tectônicos locais ou regionais. (Reis, 1996).

Outros métodos de estudo de morfologia e morfometria de plataformas continentais, também derivados de métodos de análise desenvolvidos para áreas emersas, baseiam-se em análises matemáticas da conformação geométrica da superfície, permitindo aproximações e relações das características do relevo com sua estrutura (litologia) e processos (regime de variações do nível do mar e tectônica). Cinque et al, 1995 desenvolveram um modelo de simulação relacionando a forma geométrica de perfís batimétricos com características de níveis de estabilizações do nível do mar. Trabalhos envolvendo técnicas de modelagem não lineares (ou Fractais) também tem sido utilizada com bons resultados tanto no que se refere a análises morfológicas (Her- 
zfeld \& Overbeck, 1999 e Mandelbrot , 1988) quanto na relação processos/registros geológicos e geomorfológicos (Turcotte, 1997). Também na linha de modelagens de superfícies, métodos de matemática e geometria computacional tem sido utilizados para a modelagem de batimetria de plataformas continentais, tais como métodos de Vöronoi e Thiessem (Gold \& Condal, 1995 e Gold, 2000).

CARACTERIZAÇÃO DA ÁREA: O limite da área estudado é mostrado na figura 1 .

De maneira geral, a geologia do litoral do estado de São Paulo foi condicionada principalmente por dois eventos distintos: o processo tectônico Mesozóico-Cenozóico, ligado à reativação do escudo Sul Americano, responsável pelos falhamentos que condicionaram toda a escarpa da Serra do Mar e a sedimentação decorrente das sucessivas transgressões e regressões marinhas quaternárias, responsáveis pela maior parte da distribuição sedimentar do litoral.

Conforme sugerido por Almeida, 1976, a evolução tectônica da área está associada primariamente a possíveis fenômenos termais de reativação da Plataforma Sul-Americana, que ocorreram a partir do Jurássico Superior, ligados à abertura do Oceano Atlântico. Com a evolução do processo, desenvolveram-se falhamentos a oeste da Bacia de Santos, que são considerados, pelo autor, como os responsáveis pela subsidência da mesma, sendo associado a este processo, o soerguimento da Serra do Mar «ancestral», posicionada próxima à Falha de Santos.

O maciço rochoso sofreu então, processos erosivos retrocedendo até a sua posição atual, sendo esses fenômenos os responsáveis pelo suprimento sedimentar para a bacia de Santos que, segundo Miranda, 1970, é de idade Cretáceco-Terciária e, em certos trechos, possui espessura sedimentar superior a $8 \mathrm{~km}$. Tais eventos tectônicos se estenderam até o Terciário (Almeida, 1981), expondo antigas áreas cratônicas e cinturões móveis a eventos que acabaram por produzir falhas, basculamentos, flexuras e soerguimentos que acompanharam as antigas linhas de fraqueza estrutural do embasamento, formando fossas, vales de afundamento e muralhas tectônicas, originando a Serra do Mar. Paralelamente, do Cretáceo Superior ao Paleoceno, uma gran-

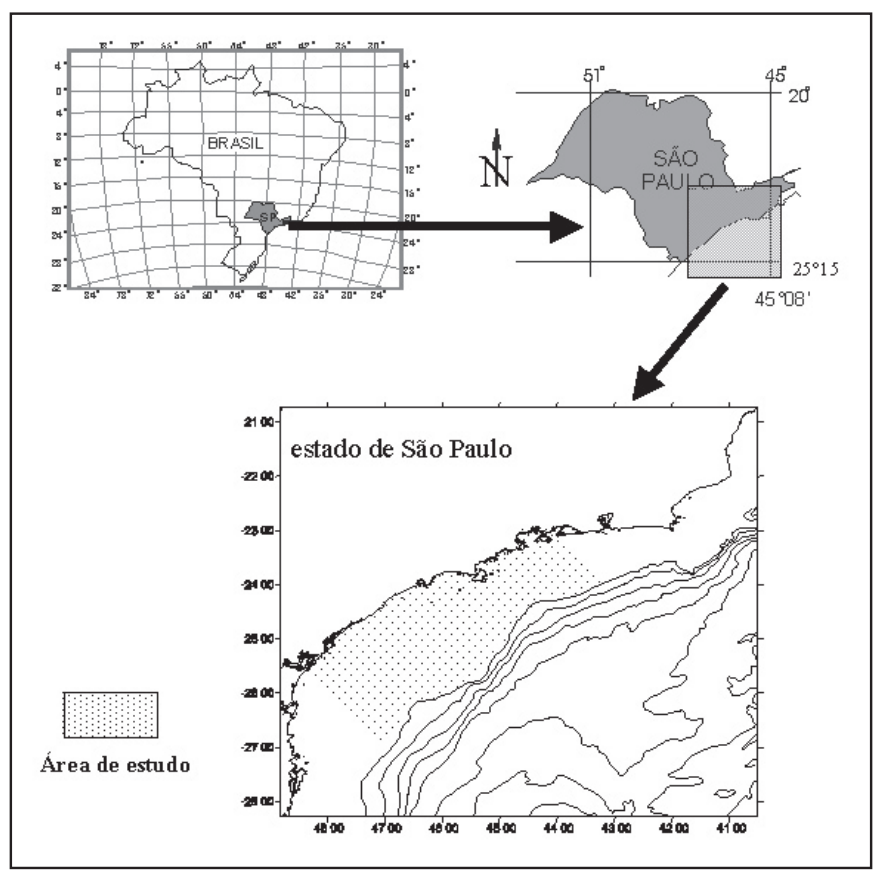

Figura 1. Localização d área de estudo de atividade tectônica ocorreu na área representada por eventos de vulcanismo alcalino atingindo boa parte do litoral, inclusive a Ilha de São Sebastião (Almeida, 1976). Esse vulcanismo é responsável pelo arcabouço mais resistente da ilha (e de outras ilhas próximas) que se comportam como testemunho do retrocesso erosivo da Serra do Mar.

A partir do Terciário Superior e Pleistoceno, a evolução da área associa-se, também, a eventos transgressivos-regressivos. As flutuações do nível do mar associadas à mudanças paleoclimáticas durante o Quaternário foram as principais causas de formação, modelagem e evolução das planícies costeiras do Brasil, com pequenas diferenças, segundo uma seqüência válida para o trecho do litoral entre o Rio Grande do Sul e Pernambuco (Suguio \& Martin, 1978).

No caso do litoral paulista, há evidências na costa de um processo transgressivo mais antigo datado de, aproximadamente, 120.000 anos AP (Suguio \& Martin, 1987), relacionado ao interglacial "Sangamoniano" tal evento é denominado de "Transgressão Cananéia" e seus registros foram observados apenas na região costeira emersa. Subseqüente à transgressão citada ocorreu um processo de regressão marinha, correspondente ao período glacial "Wisconsiniano", e que teve seu máximo regressivo há, aproximadamente 18.000 anos AP, com subseqüente máximo transgressivo há 5.100 anos AP, no qual o nível do mar chegou a $5 \mathrm{~m}$ acima do nível atual. Esta transgressão, foi denominada, para a costa de São Paulo, "Transgressão Santos". Petri \& Sugio, 1973 e Suguio \& Martin, 1978. Neste processo há evidências erosivas descritas tanto em regiões emersas quanto na plataforma continental. Estas constituídas, basicamente, de feições como vales submersos assoreados, indicando drenagens sub-aéreas pretéritas, terraços submersos e escarpas, que se relacionam a períodos antigos de estabilização do nível do mar e paleo-linhas de costa afogadas (Furtado et al.,1992).

Uma destas feições, segundo os autores, é representada pela escarpa existente ao sul da Ilha de São Sebastião, entre as profundidades de 35 e $70 \mathrm{~m}$, que se estende lateralmente para nordeste, além da Ilha Vitória, localizada a leste da Ilha de São Sebastião. Associado a essa escarpa ocorre um vale a sudoeste da Ilha de São Sebastião, que inflete para dentro do Canal de São Sebastião. Este vale apresenta uma continuidade para áreas mais profundas. A escarpa constituir-se-ia, durante a Transgressão Santos, em obstáculo ao avanço do mar no local. Há, a sudeste, um paleo-canal que, segundo Furtado et al., 1996 seria, então, a rota preferencial ao avanço do mar durante a transgressão e, constituir-se-ia, atualmente, na rota para ingressão da águas frias de fundo como a ACAS (Água Central do Atlântico Sul).

METODOS Para a elaboração do Modelo digital de terreno referente à plataforma continental do estado de São Paulo, foram digitalizados 65.296 pontos cotados oriundos de 12 folhas de bordo da DHN (Diretoria de Hidrografia e Navegação). A metodologia utilizada para a elaboração dos modelos digitais de terreno foi baseada em Burrough, 1996, Bonetti Filho e Furtado, 1995 e Conti 1998 com modificações. Os dados primários estavam originalmente na escala de 1:100.000. Em ambos os casos a densidade de pontos apresenta-se bastante alta (média de 1 ponto cotado a cada 300 metros).

As superfícies de tendência foram geradas a partir da aplicação de regressões polinomiais sobre as grades originais. Esta pode assumir, dependendo da complexidade batimétrica da área, diferentes graus de complexidade, dado pelo expoente do polinômio. Visto que a superfície teórica gerada apresenta-se como uma grade de mesmas dimensões do original (200 x 200m em ambos as áreas), é possível extrair as informações de anomalias do relevo com uma simples operação de subtração célula a célula entre as grades. Áreas onde o relevo apresenta-se acima da superfície 
teórica, as células assumem valores positivos, no caso contrário, os valores são negativos. A partir da grade gerada, foi possível calcular áreas e volumes das regiões positivas e negativas.

Além dos processos de criação de superfície teórica e anomalias do relevo, foram utilizados processos de filtragem, também chamado de "Operações de vizinhança", que se mostraram bastante úteis na análise geomorfológica das áreas. A utilização de filtros visando a análise de modelos digitais de terreno é razoavelmente comum (Thelin e Pike, 1991), entretanto, no caso de plataformas continentais, tais trabalhos são escassos. Devido ao fato das plataformas continentais apresentarem uma morfologia peculiar, onde a maior parte das feições morfológicas são bastante sutís e de dimensões distintas, o uso deste tipo de técnica pode ser extremamente útil na identificação e análise de feições submersas. No caso deste trabalho, os filtros foram utilizados para a análise da batimetria para o calculo de declividades (ou variação pendente), orientação (ou aspecto), imagens com sombreamento. Também foram utilizadas operações de geração de perfis (ou transverse) na e imagens em 3D com textura.

Quanto ao processo de geração de paleo-drenagem, os algoritmos mais utilizados em modelagem de terreno não costumam apresentar bons resultados, dada a complexidade das regiões de plataformas continentais. Contrariamente às áreas emersas, o processo gerador das feições, não mais se faz presente, logo os registros de antigos vales formados em períodos de regressão marinha e escavação sub-aérea apresentam, na maior parte dos casos, formas irregulares e descontínuas. Deste modo, é necessário uma série de processamentos, entre os quais destacam-se a aplicação de filtros do tipo "passa alta" (ou realces) que ressaltam estruturas de maiores dimensões e permitem a identificação das maiores faixas de entalhes e de processos de homogeneização planar (pit removal) que removem, do modelo, depressões localizadas que alterariam a continuidade de uma feição de escoamento (Jenson e Domingues, 1988). Executadas as operações de pré processamento na grade original, foram geradas os eixos dos sistemas de drenagem da área. Tal processamento gera um produto que, dada uma determinada dimensão mínima de canal, representa todas as feições do tipo "vale" derivada do arquivo original, resultando em uma grande quantidade de informações indistintas. Aplicando-se a este arquivo uma operação de reclassificação, foi possível hierarquizar os eixos de entalhes em ordens de grandeza segundo a hierarquização de Strahler (Strahler, 1952 apud. Tarboton \& Ames, 2001): Com o encontro de canais de primeira ordem, forma-se um de segunda ordem e assim por diante. No caso da área estudada, foram identificadas quatro ordens.Para a melhor análise dos fatores geomorfológicos da área e visto que os sistemas de ordem inferiores $\left(1^{a}\right)$, devido a sua dimensão, podem ter sido gerados baseados em imperfeições do modelo, foram mantidas para a análise apenas os canais de $2^{\mathrm{a}}$, $3 \mathrm{a} \mathrm{e} 4^{\mathrm{a}}$ ordens. Tais sistemas de paleo-vales foram associados à atual rede de dreagem a partir de correlações com imagens de satélite Landsat -7 (sensor ETM+)

Foram também utilizados dados de sedimentos superficiais com intuito de observar um padrão na distribuição da textura do substrato. Os dados relativos aos parâmetros sedimentares de superfície foram obtidos através do banco de dados sedimentológico do grupo de Oceanografia Geológica IOUSP, a partir de uma série de 15 levantamentos oceanográficos entre 1975 a 1998. Foram analisados os parâmetros granulométricos de 590 amostras e obtidas informações a respeito do diâmetro médio, porcentagem de argila, silte, areia e carbonatos.

Todas as informações obtidas, foram armazenadas em um banco de dados em ambiente SIG e convertidos em planos de informações (PIs). A listagem dos PIs utilizados segue:

Planos de Informações morfológicos (relativos à topografia):

- Paleo-dernagem

- Profundidades

- Declividade

- Anomalias (em relação à superfície de tendência)

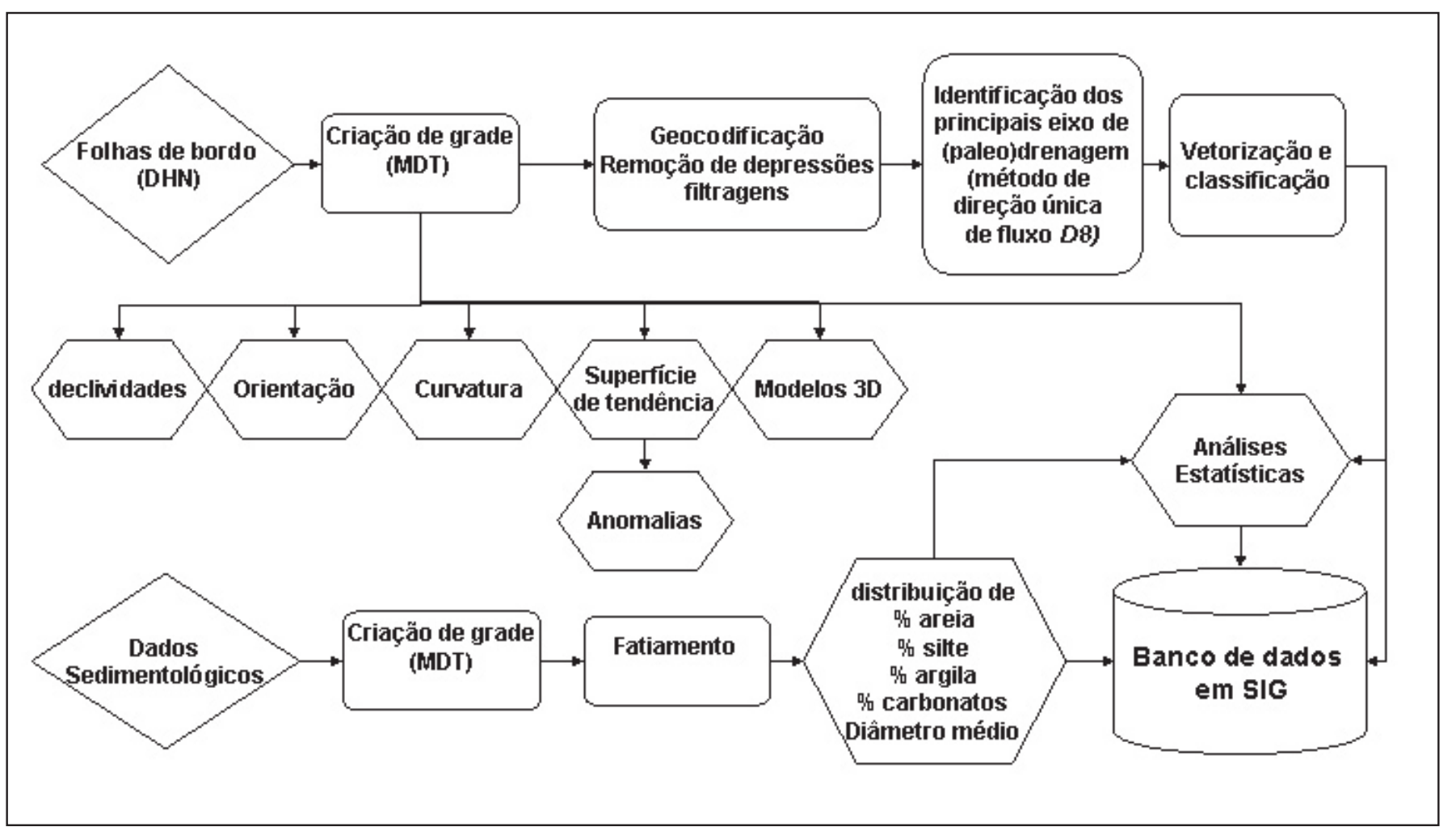

Figura 2 .Esquema metodológico de tratamento de dados do presente trabalho. 
Planos de Informações Sedimentares (relativos à textura do sedimento de fundo)

- Diâmetro médio

- Grau de seleção

- Porcentagem de areia

- Porcentagem de silte

- Porcentagem de argila

- Porcentagem de carbonatos

A partir da interação dos planis de informação, foi possivel estabelecer uma série de operações de classificações envolvendo dois ou mais PIs. Foi utilizada, para tal, a técnica de Análise de Agrupamento (Cluster Analysis) que possibilitou a confecção de um mapa de classe de similaridades morfo-sedimentares. O esquema metodológico deste trabalho é apresentado na figura 2.

RESULTADOS A partir das analises morfológicas, foi possível extrair uma série de informações ligadas ao processo evolutivo que modelaram a plataforma continental, principalmente no que se refere ao Quaternário Tardio.

Observando as feições de escala regional, ou seja, ocorrentes em toda a área, foram identificados, de maneira bastante precisa, três conjuntos de feições associadas a profundidades superiores a 100 metros. Observa-se uma grande porção de terreno mais irregular entre as isóbatas de 120 e 160 metros. Tal formação corresponde a depósitos de banco de algas calcáreas, ainda pouco estudadas e descritas superficialmente em Furtado et al. (1997).
Observa-se, também, que os eixos de paleo-vales, sofrem uma clara inflexão nesta área indicando a presença de possíveis obstáculos, provavelmente cordões arenosos. A ocorrência de tal conjunto de feições morfológicas é indicativa de um período de estabilização bastante claro, estando, pela posição em que se encontra, correlacionado com o máximo regressivo de 18 a $20 \mathrm{ka}$, em concordância espacial com diversas evidências em todo o mundo (Yokoyama et al. 2000). Uma faixa adjacente, na posição de 90 metros pode ser correlacionada com um nível de estabilização relativo a $12 \mathrm{ka}$ antes do presente (Corrêa, 1996).

Foi possível identificar também, a partir das informações batimétricas, além das feições associadas à faixa de estabilização de 120 metros, mais três zonas que estariam associadas a estabilizações do nível do mar com maiores continuidades. A primeira, na profundidade de aproximadamente 75 metros, apresenta registros na região norte e sul da área estaria correlacionada ao período de estabilização de $11 \mathrm{ka}$ antes do presente. A segunda, apresentando uma grande continuidade espacial em quase toda a área, apresenta uma forte correlação com a presença da falha de Santos, que condicionaria o relevo de modo a encaixar a linha de costa sobre irregularidades topográficas associadas a essa feição tectônica, sendo possível correlacionar tal faixa ao período de estabilização de 9ka AP.

Há também uma terceira faixa de ruptura de relevo na profundidade aproximada de 20 metros. Furtado et al, 1998, dataram amostras de arenitos praias (beach rocks) em profundidades de 13 metros em 8 kanos A.P. Tal feição pode estar associada também

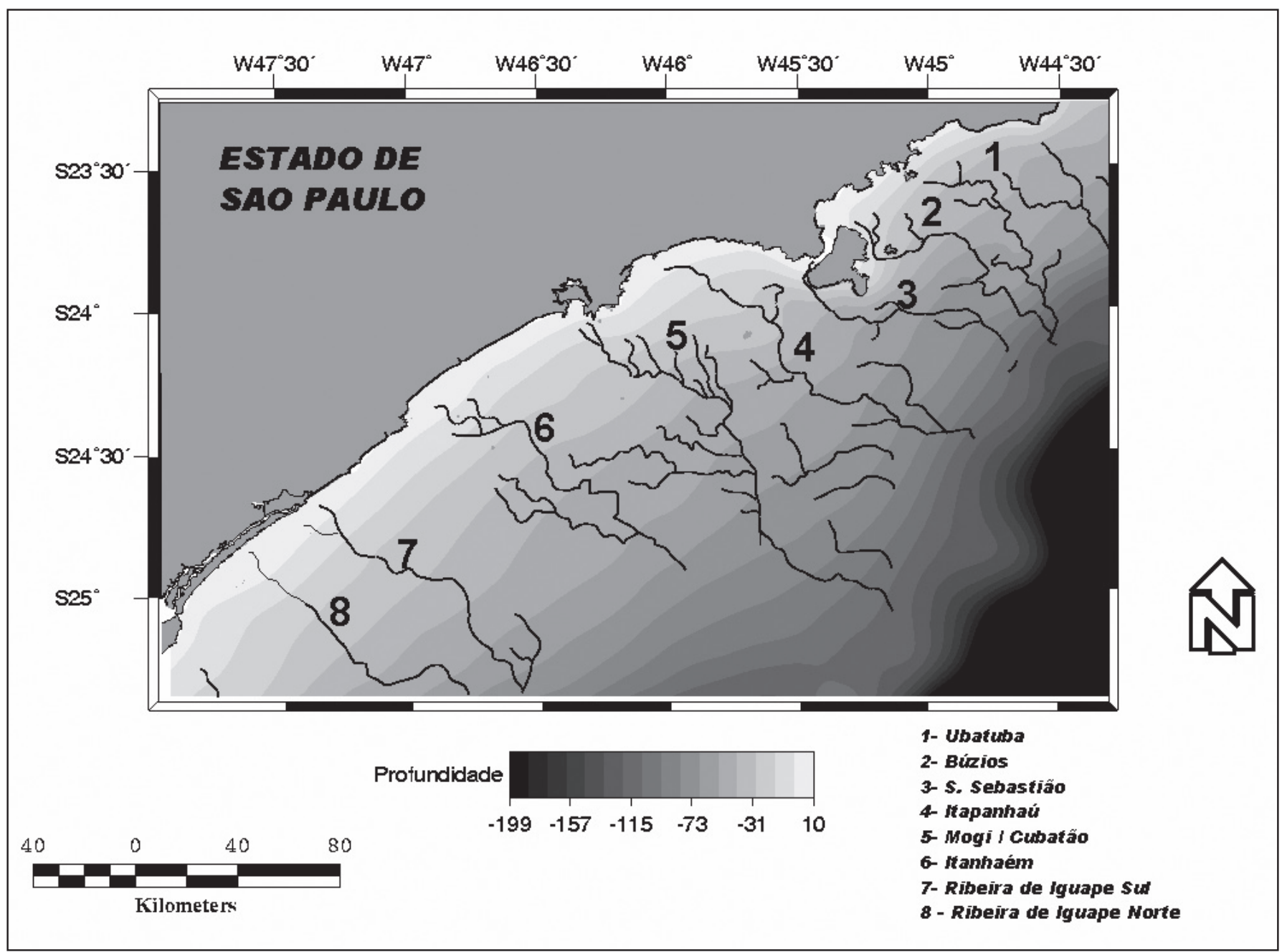

Figura 3. Localização dos principais sistemas de paleo-vales na plataforma continental do estado de São Paulo. 
a mecanismos hidrodinâmicos atuais, que podem ter retrabalhado ou realçado esta feição (Furtado et al. 1992). Um pouco mais tênue, seria uma faixa na profundidade aproximada de 60 metros indicada por algumas feições de terraços/declives localmente por indícios relativos ao comportamento da paleo-drenagem (deslocamento e possíveis áreas de migração de canais).

Quanto à distribuição das paleo-drenegens, também se observa que há uma boa correlação entre as atuais desembocaduras dos principais canais de drenagem e os eixos dos principais paleo-vales, identificados a partir do MDT. Tais resultados sugerem fortemente um padrão de prolongamento dos cursos fluviais atuais até regiões mais externas da plataforma, escavados em períodos regressivos.

Foram identificados 7 sistemas de quarta ordem (figura 3) , sendo todos eles, facilmente identificáveis com a rede drenagem atual. Outra característica geral marcante é o deslocamento que todos os canais sofrem, para norte ou para sul, nas regiões onde há zonas de maiores declividades, principalmente no que se refere à faixa de 40 metros, indicando que tal feição foi um importante condicionante da geometria da drenagem.

Na região norte da área devido à proximidade dos contrafortes da Serra do Mar em relação a posição atual da linha de costa, não há o desenvolvimento de redes de drenagem proeminentes, sendo que os maiores rios da área apresentam dimensões reduzidas, tanto geometricamente quanto em termos de fluxo. Porém, em uma situação de nível do mar abaixo do atual, uma extensa planície costeira foi formada, permitindo a captação desse grande numero de pequenas drenagens, em um sistema de um canal de maiores dimensões. Neste caso, pode-se observar que o canal não recebe um numero muito alto de afluentes de $2^{\mathrm{a}} \mathrm{e}$ $3^{\text {a }}$ ordem, e apresenta uma forma mais irregular, se comparado com os outros canais identificados.

Mais ao sul, um canal de grandes dimensões tanto em comprimento como em seção. Foi descrito em diversos trabalhos como Zembrusky, 1979 e Furtado et al., 1996. É associado provavelmente ao rio Juqueriquerê cuja foz atual localiza-se ao sul da enseada de Caraguatatuba apresentando continuidade através do Canal de São Sebastião. Analisando a batimetria da porção sul da Ilha de São Sebastião, observa-se que as maiores profundidades da área ocorrem na extremidade do canal e ao longo do eixo do paleo-vale. Outra característica marcante desta feição em relação a dinâmica atual é o condicionamento que ela exerce na entrada da Água Central do Atlântico Sul (ACAS) na região, atuando como rota de ingressão de águas mais frias (Conti 1998).

Em direção ao sul, o vale seguinte está correlacionado com o sistema estuarino do Canal de Bertioga cuja maior contribuição é do Rio Itapanhaú. Este vale, apresenta uma continuidade bastante grande, inclusive nas porções mais externas da plataforma continental. Apresenta uma baixa sinuosidade e pouca confluência de canais secundários, diferente do que ocorre com o vale associado ao estuário de Santos, cujas maiores contribuições são dos rios Mogi e Cubatão. Observa-se, nesse caso, a presença de uma série de canais juntando-se ao eixo principal.

Para o sul, observa-se, claramente a continuidade do rio Itanhaem, porém, a falta de dados na região ao sul, impede a análise mais detalhada de um grande canal afluente que provavelmente está associado ao rio Una.

Associam-se ao sistema do rio Ribeira de Iguape, duas feições de paleo-vales paralelas distantes aproximadamente $5 \mathrm{~km}$ entre si. Conti e Furtado, 2002 observaram, a partir da presença de feições características observadas a partir de imagens de satélite na planície costeira adjacente, que ambos os vales corresponderiam ao rio Ribeira de Iguape. O rio teria produzido em um primeiro momento o vale mais ao sul e um segundo vale mais ao norte, cuja posição converge para a desembocadura atual. Há evidências que estes eventos ocorreram em períodos glaciais distintos.

No que se refere à distribuição do sedimento superficial, como ocorre com a batimetria, é possível notar 3 regiões individualizadas no que se refere à distribuição regional deste parâmetro. Na região Sul, correspondente a plataforma continental da região de Cananéia/Iguape, o sedimento apresenta um diâmetro médio correspondente a areia fina com manchas isoladas de silte. Na porção central da área, a plataforma continental da região de Santos, há uma preponderância de areias muito finas e finas, com distribuição razoavelmente homogênea, com uma clara tendência ao acúmulo de material fino nas porções mais profundas onde depositam-se sedimentos lamosos.

Na Região norte, correspondente a Plataforma continental ao norte da Ilha de S. Sebastião, o padrão de deposição é muito mais complexo. Nota-se que na porção mais rasa que 60 metros, uma predominância de areia muito fina intercalada com faixas de areia fina e, em pontos isolados, junto às regiões costeiras, ocorrem manchas de areia média e grossa. Associada a ilha de São Sebastião e a zona de sombra às ondas vindas de sul, relacionados a maior dinâmica de sistemas frontais, ocorrem depósitos de material lamoso. Observa-se também, na região de plataforma externa, a clara relação entre o aumento de profundidade e diminuição na granulometria dos sedimentos, sendo que a isóbata de 120 metros praticamente delimita a zona de predomínio de areia a partir da qual o sedimento passa a ser fundamentalmente lamoso.

Estando todos os planos de informações armazenados e referenciados na mesma base foi possível, a partir de técnicas diversas, o agrupamento desses dados em classes que apresentam similaridades. A criação dessas classes permitiu uma melhor interpretação das informações, já que agrupa e sintetiza as informações analisadas. Foi criado, um mapa de classificação em que 7 classes foram geradas (figura 4). A tabela 1 apresenta um resumo das principais características observadas, em cada classe, que auxiliaram em sua denominação.

CONCLUSÕES Os recentes avanços nas tecnologias de coleta de dados aliados aos recentes projetos de levantamentos de informações ligadas à oceanografia geológica no Brasil, tem levado a um grande aumento na produção de informações e, como consequência, uma grande demanda por sistemas que possibilitem o gerenciamento, análise e interpretação destas informações. Este trabalho teve como premissa, a combinação de técnicas de análises morfométricas clássicas, na caracterização de geoindicadores morfológicos, com a utilização de sistemas de informações geográficas e modelagem digital de terreno. Tais técnicas permitiram a identificação, inferência e classificação de uma série de feições relacionadas, principalmente, com processos sub-aéreos e evolução do nível do mar ao longo do Quaternário Tardio e a integração destes resultados com informações da composição e textura do sedimento de fundo.

Foi observado que a configuração atual da plataforma continental obedece a um padrão em que, tanto a topografia quanto o sedimento de fundo, são dispostos segundo uma lei de escala hierarquizado em três níveis, a saber:

$1^{\circ}$ nível. Representa a configuração geral da plataforma continental. Pode ser representada pelo plano de tendência topográfica e sedimentar. Quanto à topografia, varia na ordem de $0,04^{\circ}$ em direção ao talude e é fundamentalmente reflexo da evolução tectônica regional da margem continental sudeste do Brasil e da evolução estratigráfica subseqüente. O padrão sedimentológico do substrato apresenta, também, uma configuração regional média de granodecrescência no sentido do talude.

Deste modo, pode-se dizer que as variáveis cuja variação se dão nesta escala são a "Batimetria", "diâmetro médio do sedi- 
Tabela 1. Características das classes morfossedimentares geradas.

\begin{tabular}{|c|c|c|}
\hline CLASSE & PRINCIPAIS CARACTERÍSTICAS & OUTRAS OBSERVAÇÕES \\
\hline P1. & $\begin{array}{l}\text { - É a classe com menores profundidades } \\
\text { (não mais que } 36 \mathrm{~m} \text { ) } \\
\text { - } \quad \text { predominância de areia }(97 \%) \text {, } \\
\text { conseqüentemente menos silte e argila } \\
\text { - Menor quantidade de carbonatos (6\%) }\end{array}$ & 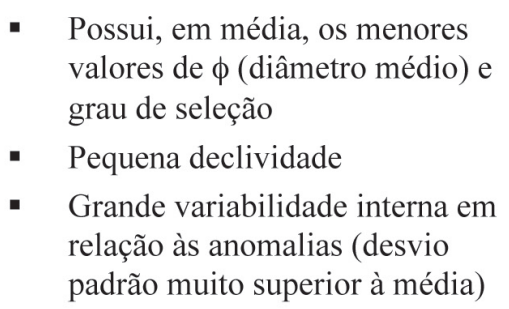 \\
\hline P2. & $\begin{array}{l}\text { - Semelhante à classe P1 em relação à } \\
\text { composição "areia, silte, argila", apesar } \\
\text { da maior profundidade (variando de } 24 \\
\text { a } 74 \mathrm{~m} \text { ) }\end{array}$ & $\begin{array}{l}\text { - Tem em média, a menor } \\
\text { declividade } \\
\text { - Valores pequenos de } \phi \text { (diâmetro } \\
\text { médio) e grau de seleção }\end{array}$ \\
\hline P3. & $\begin{array}{l}\text { - Apresenta, em média, a maior } \\
\text { declividade }\left(1,7^{\circ} \text {, enquanto as demais }\right. \\
\left.\text { classes têm médias inferiores a } 1^{\circ}\right) \\
\text { - } \quad \begin{array}{l}\text { É a mais homogênea em relação às } \\
\text { anomalias (menor variabilidade) }\end{array} \\
\text { - Tem a } 2^{\mathrm{a}} \text { menor profundidade (não } \\
\text { mais que } 52 \mathrm{~m} \text { ) }\end{array}$ & $\begin{array}{l}\text { - Valores intermediários de } \phi \\
\text { (diâmetro médio) } \\
\text { - Tem pouco mais da metade de } \\
\text { areia e } 34 \% \text { de silte }\end{array}$ \\
\hline P4. & $\begin{array}{l}\text { - É a maior classe }(30 \%) \\
\text { - Apresenta quase sempre valores } \\
\text { intermediários em comparação às } \\
\text { demais classes }\end{array}$ & $\begin{array}{l}\text { - } \quad 70 \% \text { de areia } \\
\text { - } \quad 27,5 \% \text { de carbonatos } \\
\text { - } \quad \text { Semelhante à classe P3 quanto } \\
\text { ao valor de } \phi \text { (-diâmetro médio) }\end{array}$ \\
\hline P5. & $\begin{array}{l}\text { - Têm os maiores teores de argila }(30 \%) \\
\text { e o menor de areia }(<10 \%) \\
\text { Em média, tem os maiores valores de } \phi \\
\text { (diâmetro médio) }\end{array}$ & $\begin{array}{l}\text { - Maior valor médio de grau de } \\
\text { seleção }\end{array}$ \\
\hline P6. & $\begin{array}{l}\text { - Maiores teores de carbonatos }(70 \%) \\
\text { - } 2^{\mathrm{a}} \text { maior profundidade (pelo menos } \\
100 \mathrm{~m})\end{array}$ & $\begin{array}{l}\text { Valores altos de anomalias de } \\
\text { relevo } \\
\text { Mais da metade de silte e o } \\
\text { restante quase que igualmente } \\
\text { distribuídos entre areia e argila }\end{array}$ \\
\hline P7. & $\begin{array}{l}\text { - } \quad \text { Maiores profundidades } \\
\text { - } \quad \text { Predominância de silte }(83 \%) \\
\text { - } \quad \begin{array}{l}\text { Maior média de anomalias, apesar da } \\
\text { grande variabilidade }\end{array}\end{array}$ & $\begin{array}{l}\text { - } \quad 2^{\mathrm{a}} \text { maior declividade } \\
\text { - } \quad \text { tem a menor quantidade de areia } \\
\text { (apenas } 4 \% \text { ) } \\
\text { - } 35 \% \text { de carbonatos }\end{array}$ \\
\hline
\end{tabular}

mento", "grau de seleção" "porcentagem de areia, silte e argila". Estes padrões podem ser associados, por analogia, ao $2^{\circ}$ táxon do relevo, ou "Unidades Morfo-esculturais" da classificação proposta por Ross, 1992 (O 1º́xon, ou Unidade Morfo-estrutural, corresponderia neste caso à Margem Continental do Embaiamento de São Paulo.). São bem representados pelas classes "P1", "P2" e a parte interior da "P4" (tabela 1).

$2^{\circ}$ nível. Corresponde a padrões anômalos de configuração da topografia e distribuição sedimentar, em relação ao padrão regional do $1^{\circ}$ nível. Apresentam dimensões da ordem de dezenas de quilômetros de extensão e são mais associados a distribuição de carbonatos e anomalias do relevo. Por serem derivadas da quebra de padrão, em relação á tendência regional, tem sua origem, e/ou evolução, associadas a eventos de meso-escala, tanto no que se refere à dinâmica atual quanto à processos eustáticos.

A posição da linha de costa, durante o período de máximo regressivo, parece ser um fator preponderante na configuração destes padrões, tanto no que se refere à disposição da faixa de carbonatos na plataforma externa (individualizada pela classe P6), quanto à faixa de composição anômala em relação à tendência de distribuição do diâmetro médio do sedimento nas porções mais externas da classe "P4". A região de anomalias topográficas negativas associadas ocorrência de lamas transgressivas, cuja origem está provavelmente associada ao regime transgressivo pós Ultimo Máximo Regressivo, individualizada na classe "P5" e também pode ser classificada como de $2^{\circ}$ nível, assim como padrões morfo-sedimentares associados à circulação de meso-escala, como vórtices e fluxos baroclínicos (ressurgências). Seguindo a analogia com a classificação de Ross (op. cit.) tais padrões poderiam ser enquadrados como pertencentes a um $3^{\circ}$ táxon, ou "unidades morfológicas" ou, ainda, "tipos de relevo".

$3^{\circ}$ nível. É correspondente às formas de relevo de dimensões 


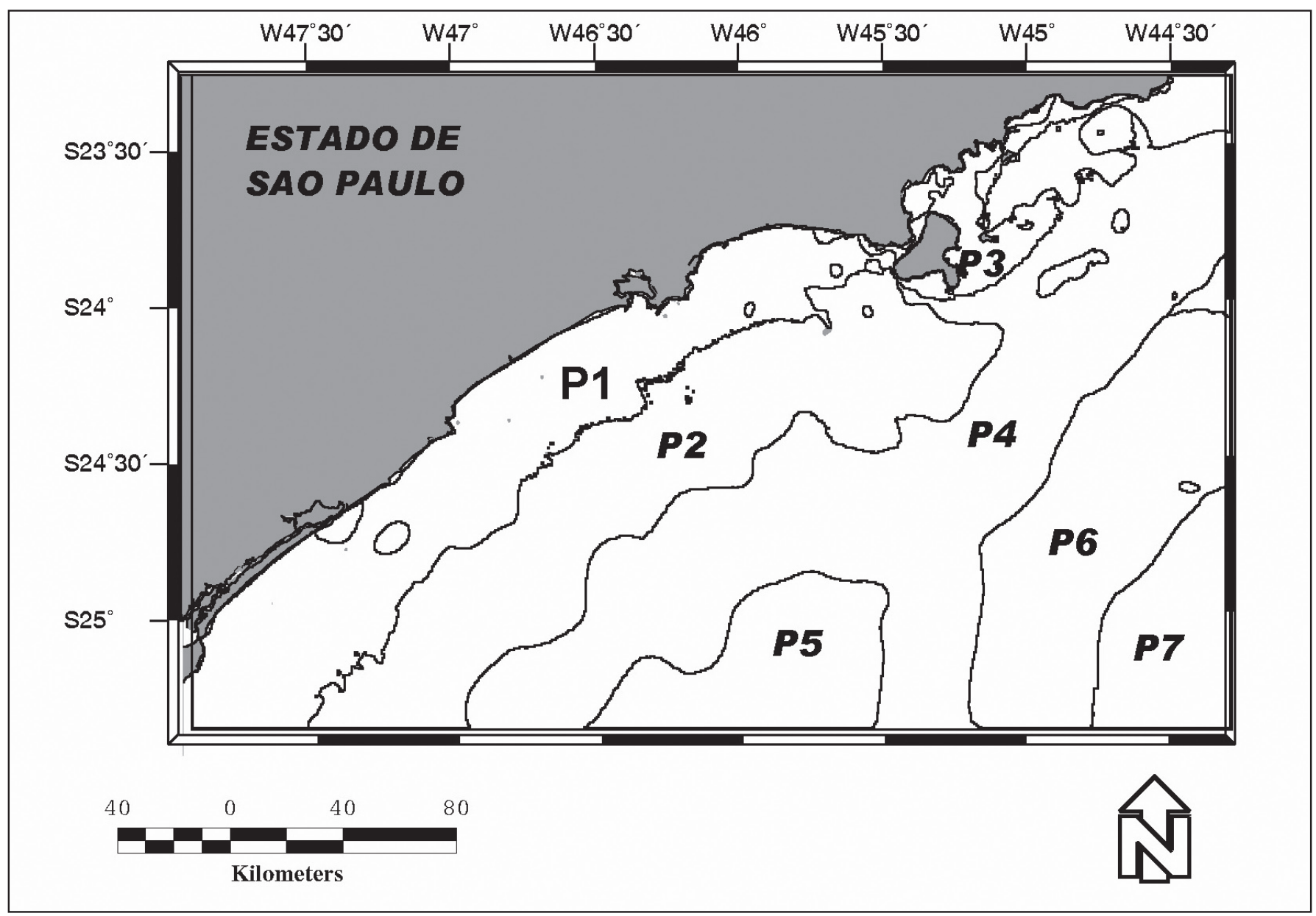

Figura 4. Distribuição espacial das classes de similaridades morfossedimentares.

mais reduzidas, da ordem de quilômetros ou dezenas de quilômetros. São produtos, fundamentalmente, de processos eustáticos ou associação destes com padrões estruturais. É representado, essencialmente pelas feições de paleo-vales e de rupturas de relevo regionais e locais. No que se refere à distribuição sedimentar, este nível está associado a padrões de sedimentação local, ligados, principalmente, a influência de desembocaduras de rios e áreas protegidas da ação de ondas, ou seja, da dinâmica atual.

Embora trabalhos realizados anteriormente na área, como, principalmente, os de Zembrusky, 1979 e Rodrigues et al. 2001 tenham apontado para resultados globais similares ao do presente estudo, este colaborou para uma normalização dos dados à mesma base e escala e, ainda, possibilitou um enfoque mais quantitativo dos parâmetros morfológicos e sedimentares. A metodologia desenvolvida nesta pesquisa deve, entretanto, ser aplicada com certos critérios para outras áreas onde fatores geomórficos como tectônica, predominância de construções carbonáticas e altas taxas de sedimentação podem distorcer e/ou mascarar feições morfo-sedimentares.

Agradecimentos Este trabalho está ligado ao sub-programa de Oceanografia Geológica do projeto "Dinâmica do Ecossistema de plataforma da região oeste de Atlântico Sul (DEPROAS) do programa de núcleos de excelência - PRONEX (CNPq/FINEP) Os autores agradecem a FAPESP pelo financiamento do projeto (Proc. 99/01827). Este trabalho está associado ao projeto IGCP 4646 - "Continental Shelves during the Last Glacial Cycle" - UNESCO.1

\section{Referências}

Almeida F.F.M. 1976. The System of Continental Rifts Bordering the Santos Basin, Brazil. Anais Acad. Bras. Cienc., 48(sup):15-26.

Almeida F.F.M. 1981. Síntese sobre Tectônica da Bacia do Paraná. In: SBG, Simpósio Regional de Geologia, 3, São Paulo, Atas, vol.1.

Bonetti Filho J. \& Furtado V.V. 1996. Modelo digital de terreno aplicado ao estudo de feições costeiras submersas no litoral sul do Estado de São Paulo. Geociências, 15(02):367-380.

Burrough P.A. 1986. Principles of Geographical Information Systems for land resources assessment. Clarendon Press Oxford, New York.

Cinque A., De Pippo T., Romano P. 1995. Coastal Slope Terracing and
Relative Sea Level Changes: Deductions based on Computer Simulations. Earth Surface Processes and Landforms, 20:87-103.

Conti L.A. 1998. Aplicação de técnicas de geoprocessamento na caracterização de aspectos morfosedimentares do Canal de São Sebastião, SP. Dissertação de Mestrado, Instituto Oc. Universidade de São Paulo, SP, 83p.

Conti L.A. \& Furtado V. V. 2002. The paleo-valleys in southeastern Brazilian continental shelf: could they be older than we thought? of In: Annual Conference of "Continental Shelves during the last Glacial Cycle". IGCP (International Geological Correlation Program, Project № 464), 2, UNESCO, São Paulo, Abstracts. 
Corrêa I.C.S. 1996. Les variations du niveau de la mer durant les derniers 17.500 ans BP: l'exemple de la plate-forme continentale du Rio Grande do Sul-Brésil, Marine Geology 130(1-2):163-178.

Costa M.P.A., Alves E.C., Pacheco P.G., Maia A. S. 1988. Prováveis estabilizações do nível do mar Holocenicos em trechos da Plataforma Continental entre o norte de São Paulo e sul do Rio de Janeiro constatadas através de morfologia de detalhe. In: SBG, Congresso Brasileiro de Geologia, 35, Belém, Anais, Vol 2 p. 436-450.

Drake C.1. \& Burk C. A. 1974. Geological significance of continental margins. In: Burk \& Drake (eds.) Geology of Continental Margin. Springer e Verlag, New York, USA.

Furtado V. V., Mahiques M. M. de, Tessler M. G. 1992. Utilização de feições topográficas submersas na correlação de paleoníveis marinhos: uma avaliação. In: Congresso da Associação Brasileira de Estudos do Quaternário, 3, ABEQUA, Belo Horizonte, Anais, p. 175-186.

Furtado V.V., Bonetti Filho J., Conti L.A. 1996. Paleo river valley morphology and sea level changes at southeastern Brazilian Continental Shelf. Anais Academia Brasileira de Ciências, 68(supl.1):163169.

Goff J.A., Orange D. L., Mayer L.A., Clarke J.E.H. 1999. Detailed investigation of continental shelf morphology using a high resolution swath sonar survay: The Eel Margin, Northern California. Marine Geology, 154:255-269.

Gold C. 2000. A algorithim approach to marine GIS; In: Wrigth \& Barlett (eds.) Marine and Coastal Geographichal Informations Syste$m s$. Taylor \& Francis, London UK, 320 pp.

Gold C. \& Condal A.R. 1995. A spatial data structure integrating GIS and simulation in a marine environment. Marine Geodesy, 18:213228.

Griboulard R. 1980. Relations entre morphologie, tectonique et lithologie dans le Domaine Côtier et Sous-Marine de la Meseta Septentrionale Marrocaine. Thèse $3^{\circ}$ Cycle, Université de Bordeaux, França, 117.p

Griboulard R \& Proud'homme R. 1985. Aporte des analyses de morphometrie dans la connaissance des structures profounds en domaine oceanique, Application à deux types de marges. Réunion Spécialisée Soc. Geol. de France.

Hanebuth T., Stattegger K., Grootes P.M. -2000- Rapid flooding of the Sunda Shelf: A late-glacial sea-level record. Science, 291:10331035

Herzfeld U. C. \& Overbeck C. 1999. Analysis and simulation of scaledependent fractal surfaces with application to seafloor morphology. Computers \& Geosciences, 25P:979-1007.

Jenson S. \& Domingue J. 1988. Extracting topographic structure from digital elevation data for geographic information system analysis. Photogrammetric Engineering and Remote Sensing, 54(11):15931600.

Kowsman R.O., Vicalvi M.A., Coutinho M.G.N., Gamboa L.A.P. 1977. Modelo da sedimentação Holocênica na Plataforma Continental Sul Brasileira. In: Projeto REMAC. Evolução Sedimentar Holocenica da Plataforma Continental e Talude do Sul do Brasil. Serie Projeto REMAC 2. PETROBRÁS-CEMPES/DINTEP, Rio de Janeiro, p.7-26.

Kowsmann R.O. \& Costa M.P.A. 1979. Sedimentação quaternária da margem continental brasileira e das áreas oceânicas adjacentes (relatório final). Série Projeto REMAC 8, Petrobrás, Rio de Janeiro, $55 \mathrm{p}$.

Mac Intyre I.G., Pylkey O.H., Stuckenrath R. 1978. Relict oyster on the United State Atlantic continental shelf: a reconsideration of their usefulness in understanding Late Quaternary sea level history. Geol. Soc. Am. Bull., 89:277-282.

Mandelbrot B.B. 1998. Fractal Geometry of Nature. Ed. W H Freeman \& Co. 468p.

Millimann J.D. \& Emery K.O. 1968. Sea level during the past 35.000 yeares. Science, 162:1121-1123.
Miranda L.O.S. 1970. Geologia das Bacias na Plataforma Sul Brasileira. In: SBG, Congresso Brasileiro de Geologia, Brasília, Anais, Vol. 24, p. 129-140.

Naudin J.J. 1971. Etude morphostructurale du Plateau Continental Aquitain. Thèse $3^{\circ}$ Cycle, Université de Bordeaux I, n $936,114 \mathrm{p}$.

O'Callaghan J. F. \& Mark D.M. 1984. The extraction of drainage networks from digital elevation data, Comput. Vision and Image Processing, 28:323.

Orange D.L. 1999. Tectonics, sedimentation and erosion In northern California: submarine geomorphology and sediment preservation Potential as a Result of Three Competing Processes. Marine Geology, 154. pp 369-382.

Petri S. \& Suguio K. 1973. Stratigraphy of the Iguape-Cananéia Laggonal Region Sedimentary Deposits, São Paulo State, Brazil. Part II: Heavy Mineral Studies, Microorganisms Inventories and Stratigraphical Interpretations. Boletim do Instituto de Geociencias-USP, 4:71-85.

Prud'Homme, R. 1970. Les lingnes de contour de Thalewag. Une métode d'etude morphologique à partir des cartes topographiques. Bull. Soc. Borda. Dax., 377:77-80.

Reis, M. R. 1996. Análise Morfoestrutural Batimétrica da porção sul da plataforma continental de Santa Catarina. Dissertação de Mestrado, Universidade Federal do Rio Grande do Sul, Porto AleglreRS, 102p.

Rodrigues M., Furtado V.V., Tessler M.G., Mahiques M.M. (orgs) 2001. Atlas Sedimentológico da plataforma continental do estado de São Paulo. Grupo de Oceanografia Geológica. IO-USP. 34 p.

Suguio K. \& Martin L. 1987. Classificação de costas e evolução geológica das planícies litorâneas Quaternárias do sudeste e sul do Brasil. In: Academia de Ciências do Estado de São Paulo, Simpósio Sobre Ecossistemas da Costa Sul e Sudeste do Brasil, Síntese de Conhecimentos, Cananéia, SP. Atas.

Suguio K. \& Martin L. 1978. Formações Quaternárias Marinhas do Litoral Paulista e Sul Fluminense. In: IGUSP/SBG, International Symposium on Coastal Evolution in the Quaternary, São Paulo, Sp. Publ. $\mathrm{N}^{\circ} 1$.

Swift D.P. 1976. Continental shelf sedimentation. In: Stanley \& Swift (Eds.) Marine Sediment Transport and Environmental Manegemant. J. Wiley and Sons ed., New York, p.311-351.

Swift D.P., Mckinney T.F., Stnal L. 1984. Recognition of transgressive and post transgressive sand ridges on the New Jersy Continental Margin: discution. In: Tillman \& Simmens (Ed.) - Siliciclastic Shelf Sediments. Society of Economic Paleontologists and Mineralogists. Special Publications $N^{\circ} 34$ Oklahoma, USA.

Thelin G.P.E. \& Pike R J. 1991. Landforms of the conterminous United States a digital shaded-relief portrayal - visualizing the landscape. Special Publication, U. S. Geological Survey (USGS). Disponível em: www.usgs.gov/reports/misc/Misc. Investigations Series Maps_\%28I_Series\%29/I_2206/I_2206.html.

Turcotte D.L. 1997. Fractals and Chaos in Geology and Geophysics. 2nd Edition, Cambridge Univ Pr., 300p.

Wagle B.G. \& Veerayya M. 1996. Submerged sand ridges on the western continental shelf of Bombay, India. Evidence for late Pleistocene-Holocene sea-level changes. Marine Geology, 136:79 - 95.

Yokoyama Y., Lambeck K., Deckker P., Johnston P., Fifield L.K 2000. Timing of the Last Glacial Maximum from observed sea-level minima. Nature, 406:713-716.

Zembruscki S.G. 1979. Geomorfologia da margem continental Sul Brasileira e das bacias oceânicas adjacentes. In: H.A.F. CHAVES (ed.) Geomorfologia da margem continental Brasileira e das áreas oceânicas adjacentes. Rio de Janeiro, Projeto REMAC n ${ }^{\circ}$ 7, p. 129-174.

Manuscrito A-1615 Revisão aceita em 25 de julho de 2006 